\title{
Autorenkollektiv
}
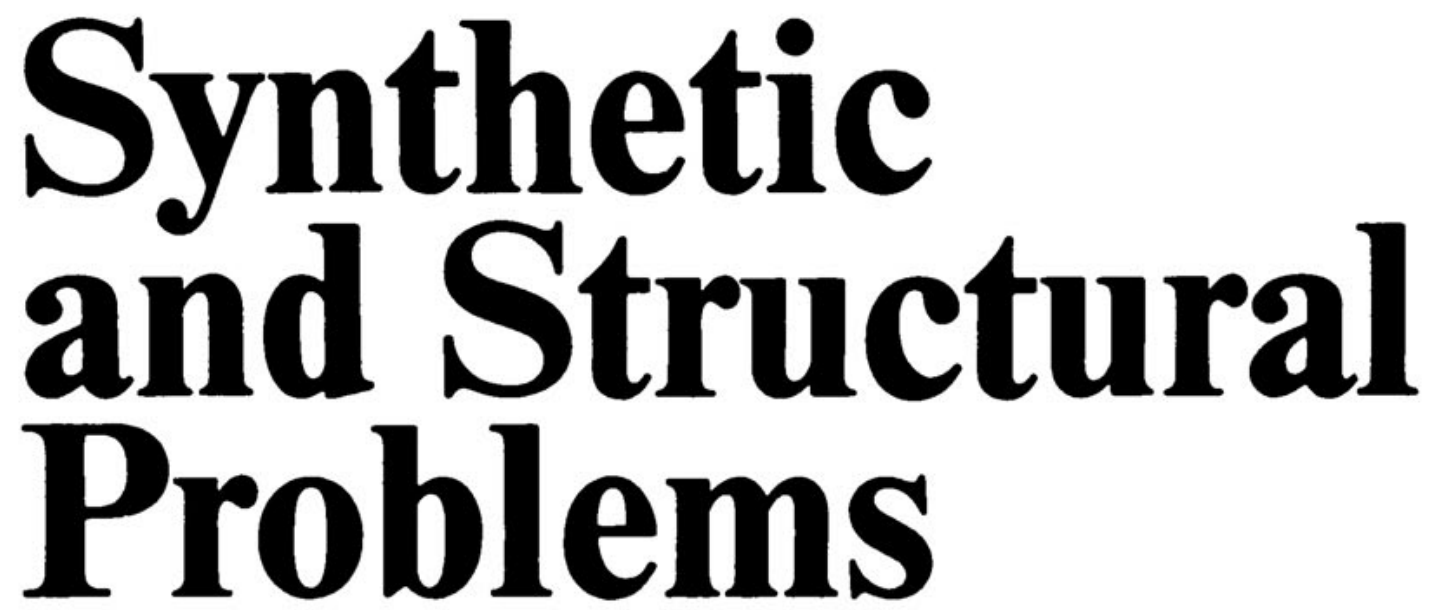

Organotitanium Reagents in Organic

Synthesis - A Simple Means to Adjust Reactivity and Selectivity of Carbanions M. T. Reetz

Lithium Halocarbenoids -

Carbanions of High Synthetic Versatility H. Siegel

Pyridinophanes, Pyridinocrowns, and Pyridinocryptands

V. K. Majestic, G. R. Newkome

New Perspectives in Polymer-Supported Peptide Synthesis

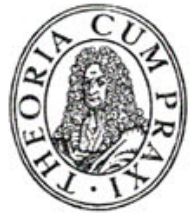

V. N. R. Pillai, M. Mutter 

Autorenkollektiv

Synthetic and Structural Problems 

Autorenkollektiv

\section{SYNTHETIC AND STRUCTURAL PROBLEMS}

With 3 Figures and 13 Tables

AKADEMIE-VERLAG · BERLIN 1983 
Die Originalausgabe erscheint im Springer-Verlag Berlin $\cdot$ Heidelberg $\cdot$ New York

Vertrieb ausschließlich für die DDR und die sozialistischen Länder

Alle Rechte vorbehalten

(C) Springer-Verlag Berlin $\cdot$ Heidelberg 1982

Erschienen im Akademie-Verlag, DDR-1086 Berlin, Leipziger Straße 3-4

Lizenznummer: $202 \cdot 100 / 552 / 83$

Gesamtherstellung: VEB Druckerei „Thomas Müntzer“, 5820 Bad Langensalza

Umschlaggestaltung: Karl Salzbrunn

Bestellnummer: $7632224(6758) \cdot$ LSV 1275

Printed in GDR

DDR 86,- M 


\section{Managing Editor:}

Dr. Friedrich L. Boschke

Springer-Verlag, Postfach 105280, D-6900 Heidelberg 1

\section{Editorial Board:}

Prof. Dr. Michael J. S. Dewar Department of Chemistry, The University of Texas Austin, TX 78712, USA

Prof. Dr. Jack D. Dunitz

Laboratorium für Organische Chemie der Eidgenössischen Hochschule Universitätsstraße 6/8, CH-8006 Zürich

Prof. Dr. Klaus Hafner Institut für Organische Chemie der TH Petersenstraße 15. D-6100 Darmstadt

Prof. Dr. Edgar Heilbronner Physikalisch-Chemisches Institut der Universităt Klingelbergstra $\mathrm{Be} 80, \mathrm{CH}-4000$ Basel

Prof. Dr. Shô Itô

Department of Chemistry, Tohoku University, Sendai, Japan 980

Prof. Dr. Jean-Marie Lehn Institut de Chimie, Université de Strasbourg, 1, rue Blaise Pascal, B. P. Z 296/R8, F-67008 Strasbourg-Cedex

Prof. Dr. Kurt Niedenzu University of Kentucky, College of Arts and Sciences Department of Chemistry, Lexington, KY 40506, USA

Prof. Dr. Kenneth N. Raymond Department of Chemistry, University of California, Berkeley, California 94720, USA

Prof. Dr. Charles W. Rees Hofmann Professor of Organic Chemistry, Department of Chemistry, Imperial College of Science and Technology, South Kensington, London SW7 2AY, England

Prof. Dr. Klaus Schäfer Institut für Physikalische Chemie der Universitāt Im Neuenheimer Feld 253, D-6900 Heidelberg 1

Prof. Dr. Fritz Vögtle Institut für Organische Chemie und Biochemie der Universität, Gerhard-Domagk-Str. 1, D-5300 Bonn 1

Prof. Dr. Georg Wittig Institut für Organische Chemie der Universität Im Neuenheimer Feld 270, D-6900 Heidelberg 1 
